\title{
GUIDO VIARO PIONEIRO DA PINTURA MODERNA NO PARANA
}

Adalice Araujo

o artista participa da sociedade como espécie de radar: não só age como sistema de detecção, captando seu meio-ambiente, como prevê a nova dimensão humana da sociedade futura. Talvez, mais do que os outros, tenha condições de reagir contra os elementos condicionadores de seu status social; por isto mesmo, denuncia-os e simultāneamente age como verdadeiro elemento desencadeador de liberdade e renovação.

Quais as circunstancias que determinariam a passagem da aculturação para a criatividade? E difícil analisă-las e mais ainda defini-las. Como sabemos, o Paraná no início do século vivia ainda a permanência do tropeirismo e a formaça de uma infra-estrutura cultural. Vinte e dois anos seriam poucos para mudar radicalmente a situação. Daí porque, para nós paranaen ses, a Semana de 22 de São Paulo foi um fenômeno isolado. Viveriamos a nossa propria semana de Arte Moderna (pelo que esse termo significa no sentido de atualização com uma realida de internacional e consequente despertar de um nacionalismo) apenas anos mais tarde, após a chegada ao Paraná, em 1933, de Guido viaro seria assim o marco inicial do lovimento de Integração da Arte Paranaense, e,jā em fins da década de 40 , teria a sua contemplação com a criação da revista "O Joaquim" por Poty, Dalton Trevisan e outros.

Assim como Minas Gerais tem Guignard, o Paraná tem Via- 
ções de artistas paranaenses é pioneiro, possivelmente em àmbito nacional, das escolinhas de arte para criancas. Como artista, Guido Viaro representa uma das mais altas expressões da pintura expressionista latino-americana. Compreendendo o ser humano com todas as suas qualidades e fraquezas, não poderia exilälo de sua arte. A sua grande fonte de inspiração só poderia ser o homem e o que o rodeia. Com visão subjetiva, respeita a integridade dos seres, embora variem técnicas e temas. Assim poderemos ver beleza mais formal em paisagens ou crianças, bem como poderemos sentir as palavras ríspidas e ao mesmo tempo humanamente poéticas com que descreve as mulheres do povo lavando roupa, ou, como boas comadres comentando a vida do próximo, ou ainda a mãe ignorante que segura o filho esquā lido nos braços, com amor instintivo e quase animal. Sempre pesquisando chegaria finalmente a libertar os elementos de um sentido meramente documental, cujo climax é atingido na ültima fase conhecida como "fase religiosa". Em vez de fazer uma arte dirigida como $\bar{e}$ a arte social dos muralistas mexicanos, faz uma arte mística, onde através da exaltação de cristo prega amor/igualdade, lutando contra as injustiças sociais. Tendo por inspiração principalmente a Via Crucis, seus personagens, mesmo aí, são tirados da vida cotidiana: gente simples porém dramática, heróica mesmo, por transcender os limites da matéria e gritar bem alto a dor coletiva que é a de todos os homens. Com uma solenidade ritual e àspera, o introduz o espectador no climax da tragédia, onde ele também passa a gemer e sofrer com os protagonistas do drama, na metamorfose 
artistica que somente os verdadeiros criadores conseguem transmitir. Segundo as palavras do prōprioviaro, a dor de cristo morto é um símbolo: "é a dor de ver a morte de nosso próprio fi lho". Dai sentirmos diante de suas crucificacōes que algo explode e ao mesmo tempo se estrangula diante de nös. No rosto convulso de Jesus em agonia está o paradoxo do ser humano - a suprema pergunta: a existência e inexistência. Assimilando todo - ideal humanista de imanéncia do divino, cristo passa ter um carāter simbólico de quem, por amor, em pleno século xx, continua carregando o grande peso do sofrimento e da misēria humana.

\section{VIARO FALANDO}

- Por que Curitiba, Prof. Viaro?

- Cheguei aqui por acidente. Em São Paulo desentendi-me com uns decoradores, fui à Estação da Sorocabana e tomei o primeiro trem que passou. Assim vim parar em Curitiba, como poderia ter ido a Porto Alegre ou Rio. Fiquei algum tempo, mas era dificil sobreviver naquela ëpoca só com a pintura. Como sempre tive a mania de estar quite com meus compromissos economicos, para ganhar $150 \mathrm{mil}$ réis, fui pintar casas de madeira. Neste interim fiz uma exposiçāo na Associação comercial vendendo cada quadro por 40 ou 50 mil réis. Escrevi um artigo no Diärio da Tarde declarando que eu não admitia aquela pintura descritiva; incontinenti os compradores me devolveram as quadrinhos dizendo que se eu pröprio atacava a minha pintura é porque não tinha valor. En fim, fiz uma sērie de besteiras e decidi ir ao Mëxico. Para tan to, economizei dois contos de réis, tendo inclusive,decinado do oferecimento do Prof. Parodi para lecionar no Colégio Iguaçu. Acontece que um bonito dia, quando estava esperando que passas- 
6e o navio que me levaria ao México, vi passar pela rua XV, Yo landa, minha esposa e mudei por completo de idëia. Corri ao co lēgio Iguaçu para perguntar se o lugar ainda estava vazio -dis seram-me que sim, e então comecei a lecionar alí. No entanto estava assediando a praça forte de Yolanda que meio a contragosto começou a falar comigo, ate que un dia sua família acabou por me conceder a possibilidade de namorā-la. Gastei os dois mil cruzeiros em flores para ela. Acabando minha reserva, aqui fiquei e aqui estou. Houve época, logo após o casamento, que lecionava em quase todos os colégios de curitiba. Lecionava 15 ou 16 horas por dia, e, quando chegava em casa, ainda desenhava ou pintava".

- Como é antes, durante e após a realizacão do quadro?

- Antes do quadro, ele é em geral digerido. Assim que é concebido adormece quase que em estado de gestação dentro do individuo. Quando ele tenta, ou quer fazer alguma coisa, solicita a esta imagem ou multiplicidade de criaturas que estão dentro de si para virem auxiliá-lo, porque se não estão dentro, de nada adiantaria faze-la visto que cada obra deverá corresponder à construção de um mundo novo. Ao começar, nem o prōprio artista sabe se podera terminar o trabalho, que embora possa ser prë-concebido deverā estar sempre subordinado à incuiçäo. Mesmo depois de finalizado e encostado à parede, por algum tempo, tem de ser submetido à própriacrítica. Se resistir é porque existem elementos bons - se nāo, é melhor destruí-1o. Eu destruo muita coisa, eu destruo... 
- Fale de sua arte, cite inclusive fases que passou.

- A princípio Viaro limita-se a responder:- "A minha arte é aquilo que é". Depois, aqui e láa, no desenrolar da conversa, diz o seguinte: - "Antes de chegar ao Brasil fiz diversas exposições ne Europa. Veneza naquela época era exclusivamente presa a um realismo objetivo; daí a razão pela qual minha conduta frente aos movimentos não foi bem sucedida. Tanto que um críti co veneziano, Sr. Scarpa, escreveu num cotidiano que minhas te las eram feitas com excessiva rudeza, porém possuiam uma manei ra prōpria e uma "inconsciência de limites" só permitida aos artistas. Embora expressionista, passei por todos os climas conhecidos, até chegar a esta fase mistica, dentro da qual me parece, ter podido fazer alguma coisa, se não grande, pelo menos representativa. No lugar de fazer uma arte social eu faço uma arte religiosa, eis a minha tematica geral. Por exemplo, a Via crucis é espiritual e ao mesmo tempo todos os acompanhan tes desse cristo que sera sacrificado representam o povo ou se ja o individuo que sofre, o unico que crê, que tem necessidade do apoio de Cristo, esse espirito superior. Então, em vez de fazer arte dirigida como è a arte social, eu traduzo através da Bíblia todo o sofrimento de Cristo, exalto o povo atraves da exaltação de Cristo que pregou o amor e igualdade entre os homens, sem diferenças raciais e economicas. Depois de cristo, São Francisco de Assis é o ünico santo humano, grande, que apa receu na casca da terra. o único que aprecio porque soube se desvencilhar do superfluo e até do necessārio. o meu problema hoje é de procura e pesquisa. Estou estudando Moisés. Paramim Moisés não é aquele descrito por Michelangelo, um deus grego, 
um homem forte, grande, maravilhoso, intocável e distante. 0 Moisés dos judeus é outro aquele que se eliminou, abjurando o próprio povo pela porcaria que fez, pela injustiça, e falta de seriedade; eu quero faze-1o antes de se eliminar. Antes de cancelar a matéria e se cornar quase espírito: deixar só os o1hos. Ver através do brilho dos olhos, a única vitalidade que deve aparecer no semideus dos judeus. Tenho procurado muito mas até agora não consegui, mas hei de fazê-1o.

- Até que ponto existe a participacão do espectador?

- Sua participação é um elemento compositivo, isto é, por assim dizer, solicitamos o auxilio do espectador como forma compositiva mas não no sentido que possa ajudar a expressão criadora. o mundo exterior só nos ajuda apös ter sido incorporado espiritualmente, porém a obra deve ser sugerida, para que - espectador participe de maneira global, complementando-a com - seu prōprio conteúdo subjetivo. Explico melhor: o excesso de matēria diminui a própria essência da obra: Esta deve ter uma base espiritual que limite o peso da matéria para que a participação do espectador, ao contemplä-la, transforme-o em co-autor da obra. Se não tiver um conteüdo este passará por ela como se fosse um cartaz. Se por acaso criassemos um trabalho fantásticamente realista em que o mundo pudesse ver o que o indivíduo queria dizer, este tornar-se automàticamente limitado e insípido como um prato de comida que já tivesse saturado pelo excesso; deve portanto possuir elementos não decididamente expli cados a serem completados pela imaginaçäo do espectador - símbolos de uma visão cosmogonica que lie apresente certa dificul dade de percepção. Ao desafiar-se a sua capacidade perceptiva, 
a obra torna-se ütil e interessante.

- Como definiria seus modelos?

- Como posso definir? São elementos sociais que perambulam por aí: Através do espírito místico procuro valorizā-los o quanto posso. Você veja o Cristo morto é um homem símbolo do amor crucificado. Todos os ascetas que o circundam são elementos da sociedade que o capitalismo e o totalitarismo des troem ou tentam destruir. Sempre foi e talvez sempre será assim. Haja vista, por exemplo, o caso da Rússia que está dis cutindo o fato da Inglaterra ter eliminado aqueles espióes do próprio territōrio. Quer dizer que a Rūssia estā tentando surrupiar a uma outra nação o esforço do próprio povo. ora, se ela justamente ostenta o título de exaltadora dos direitos do povo está cometendo uma gafe, uma indecência moral perante a humanidade Toda.Há também o caso dos tupamaros,vietcongs e, por outro lado a Rússia ajudando ärabes, e Estados Unidos os israe litas, ambos vendendo armas a um e a outro e depois ousam falar em nome da fraternidade universal: ōbviamente temos de refletir em nossa pintura alguma coisa disso tudo.

- Como foi sua experiência em Escolinha de Arte?

-Gostei e sobretudo me senti bem porque estava junto com a infância, o que me dá a sensação de prolongar minha própria vida. Escolinhas de Arte não deveriam ser um rameirão como esta atualmente ocorrendo, mas precisariam estar espalhadas nos quatro pontos cardeais da cidade,para que seu acesso fosse facultado a todos os filhos de gente pobre. Porque, justamente, os melhores elementos de nossas escolas são gente de bairro. Gente, filho de pobre gente que jamais teve carinho, ou präti- 
camente nada. Porque $\vec{e}$ ai que se encontra a verdadeira sensibi lidade e a escola permite, através da cor,da expressão nova, uma fuga ou uma realização.

- Como encara a problemática da arte?

- Arte é uma necessidade espiritual. Emanifestar os próprios sentimentos, os próprios ansios de dizer aos outros o que se pensa do mundo exterior,extravasando as necessidades in teriores. Desde o paleolítico até hoje o homem possui uma manifestação artística que se coaduna como magicismo religioso. Religião e arte se confundem, não tem limites. A criatura humana tem sempre tentado se exprimir de maneira invulgar, porém nem todos, mesmo aqueles que pensam estar fazendo arte, conseguem fazer alguma coisa sensivel que transmita algo dos anseios humanos. Falo exprimir no sentido de preencher uma lacuna humana. Talvez o problema mais sério que um jovem artista deva enfrentar seja o fator economico. Hoje os materiais custam carísimo. Se quiser fazer un trabalho grande irá gastar uma fortuna em materiais, de modo que se vê constrangido a afo gar, a reduzir, a estrangular a prōpria emotividade. 0 mercado também é restrito. A própria casa moderna, o apartamento, em geral de pequenas dimensöes,näo comportam um quadro grande; o individuo tem forçosamente que fazer um quadro pequeno, pois ocorre o fenómeno comum do "quadro complemento decorativo da parede". Não se compreende a "arte-mensagem". Efetivamente, o artista é um individualista, com sua própria sensibilidade e emotividade. Daí também a razão pela qual nảo se pode nivelar nem a arte, nem os seres, como preconizam o comunismo e os partidos totalitários. O artista é um ser estranho, um maluco e 
ao mesmo tempo um equilibrado, que sente todos os movimentos telúricos do mundo e tenta através da própria sensibilidade transmitir sua emotividade, de modo a ser ütil àquelas criaturas sensíveis; aos outros não interessa. ocorrc o mesmo em outros setores: para um indivíduo que não gosta de foot-ball é inütil falar no assunto, assim para quem não gosta de música por que falar de Debussy? Quer dizer, o mundo ainda hoje não é coletivo. Nem o comunismo nem o socialismo conseguiram arrancar o individualismo dos seres. Assim como não existem duas folhas exatamente iguais numa ärvore, não existem também duas criaturas iguais; nem mesmo irmäos que provēm de uma mesma matriz, istoé, de um mesmo ser. Cada um tem uma própria razão de ser, de pensar, de sentir.

- o que pensa da arte moderna?

- o que $\bar{e}$ a arte moderna eu não sei? Quer talvez dizer zrte contemporānea? Porém eu conheço só uma forma de arte: arte verdadeiramenti- arte, arte manifestaçáo superior de um povo, que mostra o grau de civilização a que atingiu. Devemos admitir que a arte atual, em muitos aspectos, deve ser considera da em relação à arquitetura. Dai, tambëm, compreendemos a necessidade de preencher uma função decorativa dentro das linhas rigidas e simples do funcionalismo arquitetōnico. Surgindo forçosamente uma arte de cor, de vibração visual, válida para a criatura humana já com demasiados problemas para pensar. Se num ambientedecorado modernamente nos incluirmos uma mensagem qualquer que seja, poderia criar insegurança, justamente num momento em que aquele ser afogado por um excesso de tensões de 
veria esquecer os problemas que o atormentam. Quanto a certos movimentos como a "anti-arte", considero-os estupides, maneira elegante de fazer alguma coisa diferente, para chamar atenção do püblico pseudo-intelectual.

- E a arte no futuro?

- A arte do futuro $\vec{e}$ imprevisível. Por um lado,a técnica moderna chegou a um ponto tal que se divorcia completamente da sensibilidade do povo; por outro lado, todos os caminhos já foram explorados, desde a pintura aérea, desde a pinturabidimensional à tridimensional, desde a mecanica à pesquisa de $1 a-$ boratório. Assim é dificil prever o que o futuro irá proporcio nar. Mas como o homem é sempre homem e vive como homem repetir-se-ä dentro do espaço e do tempo. Habituado que é a chorar, blasfemar e rezar, acostumado a protestar contra tudo e contra todos, $\vec{e}$ possível que a arte sofra uma volta ao primitivismo antigo, vestida de uma maneira diferentë, com palavas e símbolos diferentes; visto que o mundo não pára, ao contrário, caminha, e portanto voltar atrás seria negar toda a evolução humana. Devemos também admitir que a arte tende à industrialização, mas em forma ilustrativa e descritiva. Aliás, a prōpria musica e literatura sāo descritivas, descendo em profundidade, descrevendo a tragédia da criatura humana. Só que dentro desta amarraçäo tecnológica, o artista deverá descobrir uma nova forma para atingir a parte sensivel da criatura humana. Veja - se o abstracionismo atual que em sua funça tende a eliminar - problema psicolögico, passando a agir como uma espécie de foot-ball, de "panis-circense" dos romanos, onde, no momento em que tem fome, esquece a tudo para soltar foguetes. 
- Como encara a tecnologia e a criacāo artistica?

- A criação humana pode ser auxiliada pela tecnologia. Não pode repousar completamente nela por ser ciéncia pura. o dia em que transformarmos a arte em especulação científica, entäo até logo, estaremos perdidos. Porque eliminando o espírito, a leligiāo e a própria arte, eliminaremos tudo.

- Como é seu conceito de espaco?

- Não tenho muito conceito de espaço porque respiro mal.

- Quar a funfão da cor em seu trabalho?

- E um complemento. Você vê que o veículo de minha obra é o desenho e nảo a cor. A gravura, por exemplo, é um elemento que leva o indivíduo em profundidade; a cor é superficial, quase um elemento de ócio, de prazer. Embora não possamos viver num mundo sem cores, uma pintura totalmente apoiada nas co res, mesmo que haja temātica, será decorativa, justamente por apelar mais aos sentidos do que à razäo.

- Quais as influências em sua evolugão artistica?

- Devo confessar uma coisa, aliä, ja confessei muitas vezes. At $\vec{e} 1936$ era mediocre pintor, quando veio da Itälia De Bona com uma exposição maravilhosa - com aquele entusiasmo e aquela maneira de fazer tal - que em seis meses, modifiquei totalmente; havia descoberto a invenção! E portanto a ele que devo a transformação de minha pintura. Se formos suficientemente humildes deverímos reconhecer que inclusive os alunos nos podem ensinar coisas. Quantas vezes em poucos minutos encontram o dispositivo final vital, a renovaçäo dos problemas sofregamen te buscados: Finalmente me vali tambēm de Andersen, bastante 
técnico, cujo domínio artesanal é veículo indispensável para a projeção da sensibilidade. Sempre andando, em procura de algo mais do que ser simplesmente profissional, fiz gravuras. Continuo andando, isto é, continuo procurando.

- Que mensagem enviaria a um jovem artista?

- Trabalhar, trabalhar, trabalhar.

\section{QUEM FOI GUIDO VIARO}

Guido Batista Viaro nasce em Badia Polesine, Itälia, em 9 de Setembro de 1897, sendo filho de Santina Soldé viaro e João Batista Viaro. Na cidade natal cursa o primeiro e segundo grau. Inicia sua formação artística em Veneza tendo completado estudos em Bolonha. Em 1921 exerce o magistério de desenho na Escola de Desenho de Badia. Por algum tempo mora em Paris. Na primeira fase de sua pintura, antes de vir ao Brasil, esta demasiado preso ao realismo objetivo, tanto é que um crítico veneziano, $S r$. Scarpa, comenta que suas telas eram feitas com excessiva rudeza, porēm, possuiam uma maneira prōpria e uma inconsciência de limites só permitida aos artistas. Em 1928 desembarca no Rio de Janeiro onde permanece pouco tempo. Passa a residir em São Paulo ondo colabora como caricaturista em jor nais locais e realiza sua primeira individual. Em 1933 radica-se no paraná onde passa a exercer simultanemente as funçōes de: professor, pintor, desenhista, gravador e escultor. Em 1935 casa-se com Yolanda Stroppa tendo em 1938 um filho de nome Constantino. Em 1937 inicia uma experiência inédita no Brasil formando uma escolinha de arte no Colégio Belmiro Cesar. (Graças ao apoio da pedagoga paranaense Eny Caldeira, 
apenas em 1950 o Centro Juvenil de Artes Plásticas seria regularizado). Algum tempo após a experiência do colégio Belmiro Cesar,surge a Escola de Arte Guido Viaro, numa das dependências da Sociedade Dante Alighieri, Praça Zacarias, Em 1948 le va seus alunos à recém-criada Escola de llúsica e Belas Artes da qual é um dos professores fundadores (assim é que seus alunos particulares passam a conetituir o núcleo inicial da ārea de Belas Artes). Antes de Mcluhan, o papa da comunicação contemporānea, ele já chegara à conclusão de que a arte é essencialmente processo de comunicaça, transmitindo inclusive aos seus alunos da Escola de Belas Artes o sentidoverdadeiro de uma auto-educação: não só criando a clima de professor - animador como tambēm de aluno-pesquisador. Pode-se dizer que na épo ca viaro salva a criatividade da nova geração paranaense. Como gravador colabora na revista "O Joaquim". Em 1942, recebe uma medalha de bronze em pintura no Salão Nacional de Belas Artes. No Salão Paranaense: 1947, medalha de prata; 1951 , Medalha de Ouro; 1952, préio je viagem. Em 1960, medalha de píata, Porto Alegre; 1952, medalha de ouro, Salão do Clube Concördia; 1966 , Sala Especial no II Salão de Arte Religiosa de Londrina. Rea1 iza mostras individuais em Curitiba, Porto Alegre e Rio. Em 1966 o Departamento de Cultura publica um opusculo na Documentação Paranaense intitulado: "Guido Viaro Artista e Mestre".

Entre outras referências bibliogräficas, é citado no "Dicionário de Artes Plásticas no Brasil" de Roberto Pontual. Em 1969 é focalizado numa reportagem de "O Cruzeiro". No mesmo ano os alunos da Éscola de Belas Artes, en reconhecimento à obra do mestre, considerado pioneiro da pintura moderna no Parana, 
dãoo nome de Guido Viaro ao Diretório Acadêmico. Sua ültima expusição individual realiza-se no dia 22 de Setembro de 1971 , pouco antes de seu falecimento, ocorrido no dia 4 de novembro, do mesmo ano, em Curitiba.

A obra de Guido Viaro, o artista que amou a humanidade, continua. A sua filosofia de vida aí está, em qualquer criança que pinta expontaneamente, descobrindo en sí a aventura de criar. 


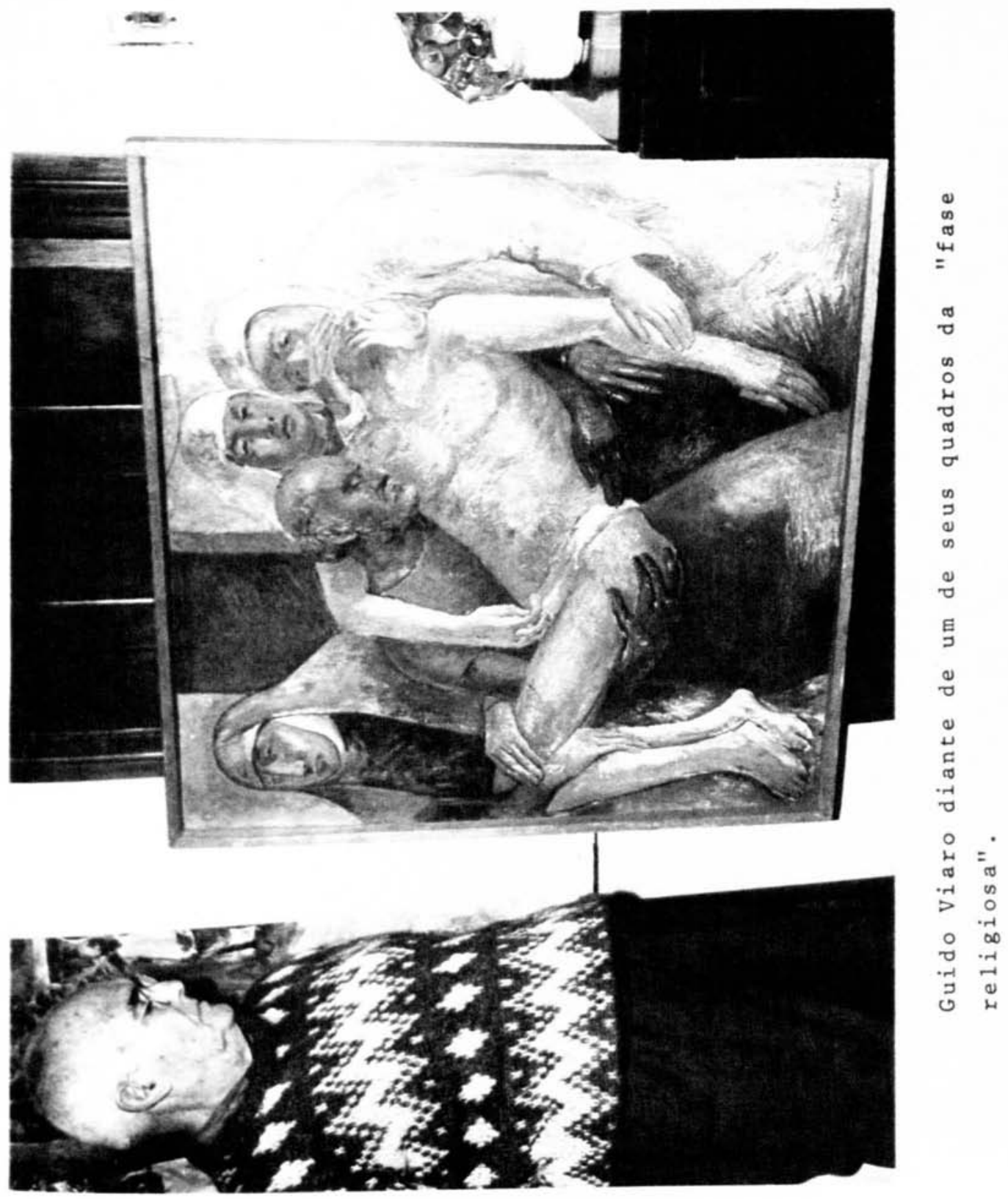

